\title{
A boronic acid-based fluorescent hydrogel for monosaccharide detection
}

\author{
Suying Xu ${ }^{1,2}$, Adam C. Sedgwick ${ }^{2,3}$, Souad A. Elfeky ${ }^{2,4,5,6}$, Wenbo Chen ${ }^{2,4,7}$, Ashley S. Jones ${ }^{2}$, George \\ T. Williams ${ }^{2}$, A. Toby A. Jenkins², Steven D. Bull ${ }^{2}$, John S. Fossey $(\bowtie)^{4}$, Tony D. James $(\bowtie)^{2}$ \\ 1 Department of Biochemistry, Faculty of Science, Beijing University of Chemical Technology, Beijing 100029, China \\ 2 Department of Chemistry, University of Bath, Bath BA2 7AY, UK \\ 3 Department of Chemistry, University of Texas at Austin, TX 78712-1224, USA \\ 4 School of Chemistry, University of Birmingham, Birmingham B15 2TT, UK \\ 5 National Institute of Laser Enhanced Sciences, Cairo University, Giza 12613, Egypt \\ 6 Higher Institute for Optics Technology, Sheraton, Cairo 17361, Egypt \\ 7 Shanghai Key Laboratory of Materials Protection and Advanced Materials in Electric Power, Shanghai University of Electric Power, \\ Shanghai 200090, China
}

(C) The Author(s) 2019. This article is published with open access at link.springer.com and journal.hep.com.cn

\begin{abstract}
A boronic acid-based anthracene fluorescent probe was functionalised with an acrylamide unit to incorporate into a hydrogel system for monosaccharide detection. In solution, the fluorescent probe displayed a strong fluorescence turn-on response upon exposure to fructose, and an expected trend in apparent binding constants, as judged by a fluorescence response where D-fructose $>$ D-galactose $>$ D-mannose $>$ D-glucose. The hydrogel incorporating the boronic acid monomer demonstrated the ability to detect monosaccharides by fluorescence with the same overall trend as the monomer in solution with the addition of D-fructose resulting in a 10fold enhancement $(\leqslant 0.25 \mathrm{~mol} / \mathrm{L})$.
\end{abstract}

\section{Introduction}

Monosaccharides are among the basic building blocks of life and play an essential role in the function of several physiological processes, including metabolism and cellular recognition [1]. The monosaccharide glucose serves as the main form of energy for tissues and cells [2]. Due to their biological importance, there has been extensive effort in the development of methods and techniques for monosaccharide detection [3-4].

Lorand and Edwards reported the ability of boronic acids to form complexes with 1,2- and 1,3- diols. In

Received October 10, 2018; accepted January 6, 2019

E-mails: j.s.fossey@bham.ac.uk (Fossey J S);

T.D.James@bath.ac.uk (James T D) addition it was discovered that D-fructose formed a $1: 1$ fructose-boronic acid complex and D-glucose formed a 1:2 glucose-boronic acid complex [5]. The strength of the boronic acid binding to monosaccharides is determined by the orientation and relative position of hydroxyl groups. In aqueous solution fructose predominates in the furanose form with a syn-periplanar pair of hydroxyl groups resulting in a strong binding constant with boronic acids [4]. As a result, a number of aryl boronic acid-based sensors have been developed for the detection of monosaccharides which exploit the difference in binding stoichiometry and inherent binding affinity to achieve either D-fructose or D-glucose selectivity [4,6-8]. More specifically, in 1994, James et al. developed an anthracenecontaining mono boronic acid derivative as a photoinduced electron transfer (PET) fluorescence probe for the detection of fructose (Fig. 1) [9]. In this system, it was discovered that ortho-aminomethylphenylboronic acid functionality facilitated the detection of fructose in neutral aqueous solution. This pioneering work has led to the development of other ortho-aminomethylphenylboronic acid-containing fluorescence sensors improving selectivity, increasing excitation/emission profile and binding affinities [10-12]. While there was never any doubt that the orthoaminomethylphenylboronic acid group was important to improve saccharide binding at neutral $\mathrm{pH}$ the mechanism of action had been under debate for a number of years [13-15]. Recently, the debate was concluded and the fluorescence enhancement on saccharide binding is caused by modulation of internal conversion resulting in different levels of quenching. Initially, before saccharide binding the free $-\mathrm{B}(\mathrm{OH})_{2}$ groups quench the fluorescence by internal 

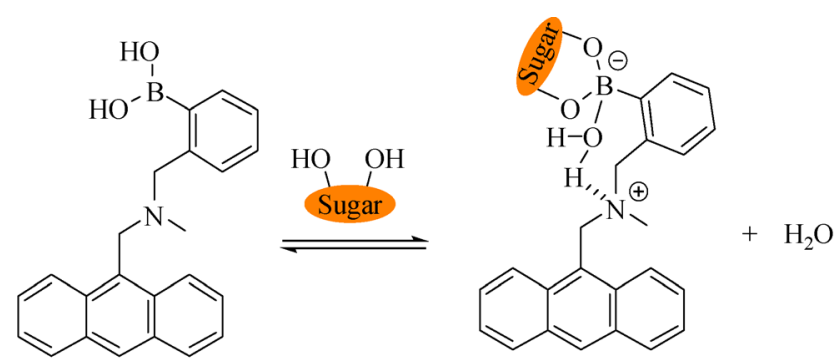

Fig. 1 Shinkai et al. anthracene-based boronic acid PET fluorescence probe for the detection of fructose

conversion, then when saccharides bind the $-\mathrm{B}(\mathrm{OR})_{2}$ groups formed have reduced internal conversion and less quenching resulting in an enhanced fluorescence [16].

The saccharide-binding properties of aryl boronic acid derivatives have been exploited as recognition motifs across a number of different domains including polymer hydrogels $[6,17,18]$. Hydrogels are three dimensionally cross-linked hydrophilic polymers, with a high ( $\sim 90 \mathrm{wt}-\%)$ water content [19]. The modification of hydrogels to contain boronic-acid binding motifs enables the physical properties of the hydrogel to be reversibly modulated through exposure to saccharide-containing stimuli, i.e., glucose responsivity [20-23]. Co-authors of this report have developed stimuli responsive hydrogels and fluorescent sensors [24-30], and as a result, we were motivated to translate a Shinkai-like anthracene-containing boronic acid sensor unit into a hydrogel sensor by linking to an acrylamide functionality, thus generating a fluorescence-on sensor hydrogel for monosaccharide detection.

\section{Results and discussion}

Whilst solution-based fluorescent sensors offer a significant advantage in terms of binding-kinetics over analogous heterogenous sensors [31]. Heterogenous immobilisation of a fluorescent sensor is preferential as it avoids contamination of the sensor in a practical situtation, i.e., in vivo [32,33]. The near-solvated nature of a hydrogel is thus an attractive alternative as they offer heterogeneity without the disadvantages associated with a solution-based system. By integrating the Shinkai et al. anthracene PET fluorescent probe into a hydrogel, we hoped to develop a fluorescence responsive boronic acid hydrogel, which could eliminate the need for an additional competitive optical reporter [33]. The desired boronic acid monomer AM-5 is shown below in Fig. 2.

AM-5 was synthesised over five steps (Scheme 1). In brief, 1,6-hexanediamine was mono-Boc protected through the dropwise addition of di-tert-butyl dicarbonate $\left((\mathrm{Boc})_{2} \mathrm{O}\right)$ to an excess of 1,6-hexanediamine, which afforded tert-butyl (6-aminohexyl)carbamate (1) in 74\% yield. To attach the desired anthracene fluorophore, 1 was stirred with anthracene-9-carbaldehyde at room temperature overnight to form an imine intermediate. $\mathrm{NaBH}_{4}$ was then added portion-wise to produce the desired secondary amine tert-butyl (6-((anthracen-9-ylmethyl)amino)hexyl) carbamate (2) in reasonable yield (48\%). Compound 2 was subsequently alkylated with 2-bromomethylphenylboronic acid pinacol ester to afford $\mathbf{3}$ in good yield (89\%). Compound 3 was then Boc-deprotected using trifluoroacetic acid, which also resulted in the partial hydrolysis of the boronate ester to form boronic acid 4, this intermediate was taken onto the next step without purification. Methacryloyl chloride was then used to afford AM-5, which was confirmed by mass spectrometry. Compound AM-5 proved difficult to characterise by NMR techniques and exhibited a broad and complex ${ }^{1} \mathrm{H}$ NMR due to the formation of "oligomeric boronic acid anhydrides" [34-35].

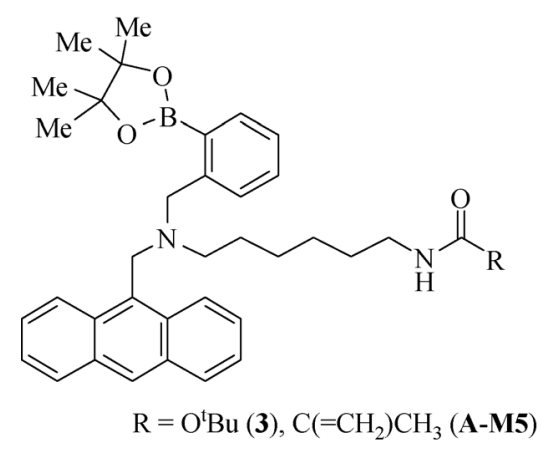

Fig. 2 Anthracene-based fluorescent monomer (A-M5) for the development of a hydrogel for the detection of monosacharides 


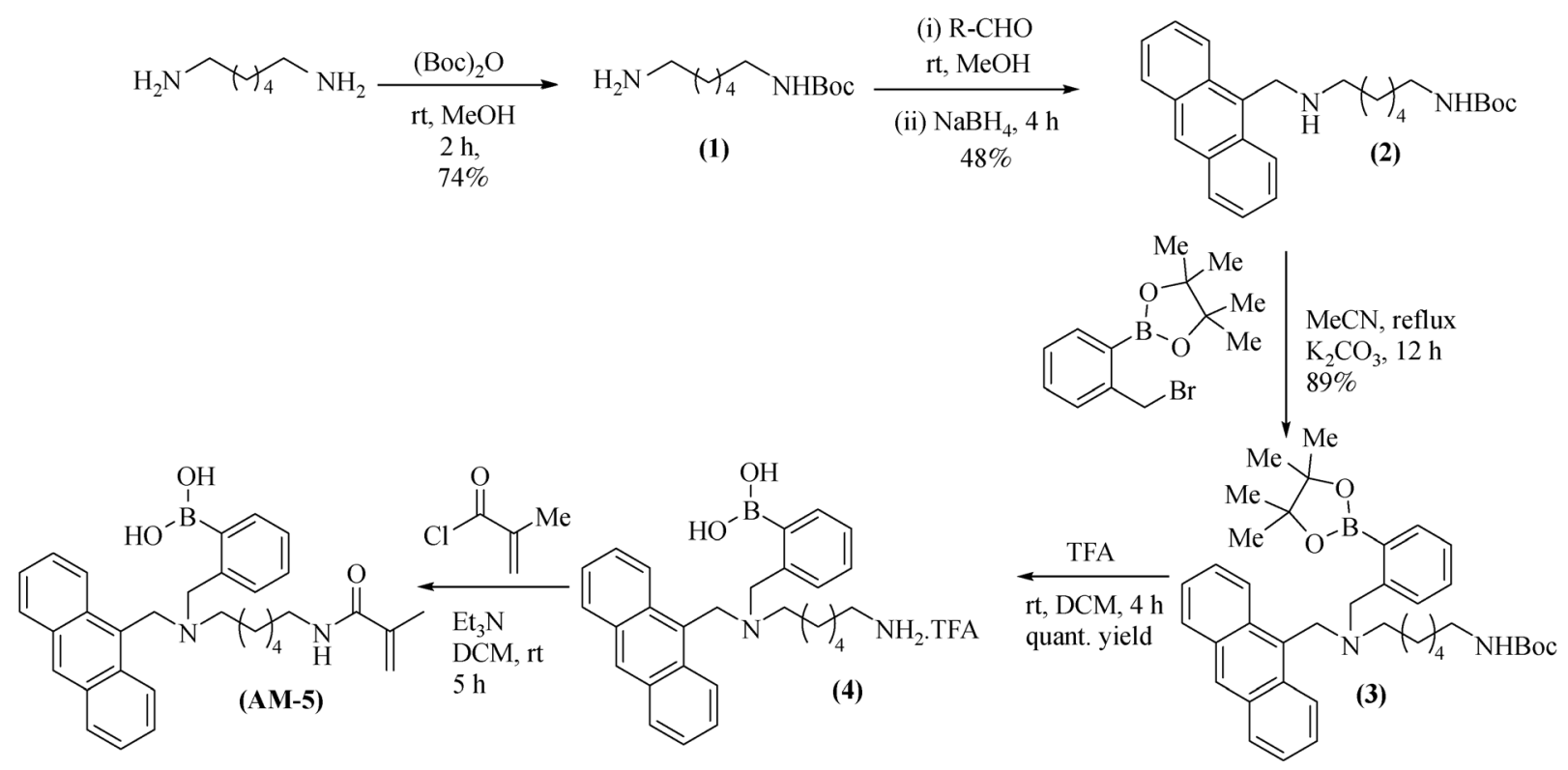

Scheme 1 Synthesis of boronic acid fluorescent probes 3 and AM-5

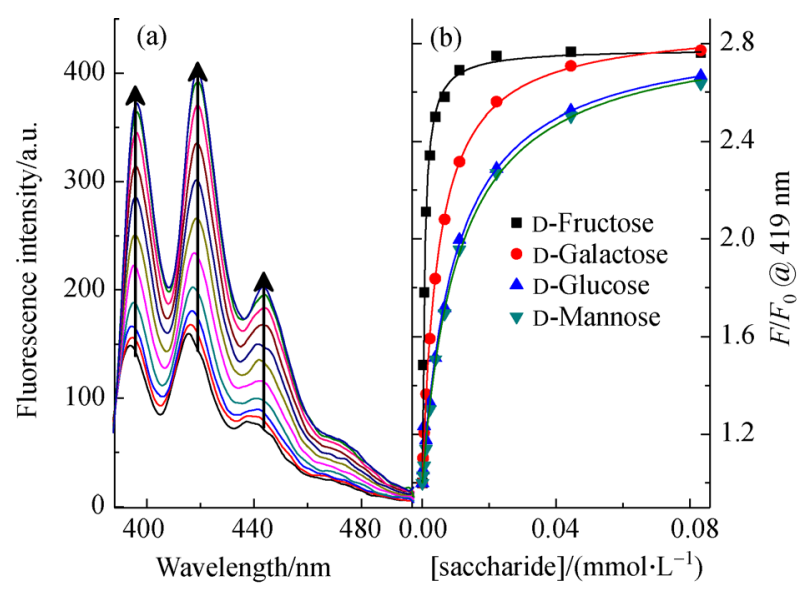

Fig. 3 (a) Fluorescent spectral changes of $3(0.6 \mu \mathrm{mol} / \mathrm{L})$ with different concentrations of D-fructose in pH 8.21 aqueous methanolic buffer solution (52.1 wt-\% methanol (KCl, $10 \mathrm{mmol} / \mathrm{L} ; \mathrm{KH}_{2} \mathrm{PO}_{4}, 2.73 \mathrm{mmol} / \mathrm{L}$ and $\mathrm{Na}_{2} \mathrm{HPO}_{4}, 2.78 \mathrm{mmol} / \mathrm{L}$ )); (b) Fluorescence intensity changes $\left(F / F_{0}\right)$ at $419 \mathrm{~nm}$ versus increasing saccharide concentration. $\lambda_{\mathrm{ex}}=370 \mathrm{~nm}$

With 3 in hand, the fluorescence properties and responses to a panel of monosaccharides were evaluated to demonstrate its sensing ability before incorporation into a hydrogel. As shown in Fig. 3(b), 3 was more sensitive towards fructose over other monosaccharides (as expected) and the binding stability constants between mono-boronic acids and saccharides followed: D-fructose $>$ D-galactose $>$ D-mannose $>$ D-glucose (Table S1, cf. Electronic Supplementary Material (ESM)). From these results, we turned our attention towards the incorporation of $\mathbf{3}$ into a hydrogel.

Hydrogels containing AM-5 were formed by copolymerisation of acrylamide and methylene bisacryla- mide in water through free radical polymerisation using ammonium persulfate (APS) and tetramethylethylenediamine (TMEDA) (cf. ESM for full detailed procedure). For the evaluation of the fluorescence response of the hydrogel towards different monosaccharides, each hydrogel was placed into a monosaccharide solution for $2 \mathrm{~h}$ (Note: $2 \mathrm{~h}$ was chosen since at this time point no further increase in fluorescence intensity was observed after addition of monosaccharides).

Acrylamide-based hydrogels consisting of AM-5 were exposed to increasing concentrations of fructose and a significant fluorescence enhancement was observed ( 16-fold) as shown in Fig. 4, the selectivity order for 


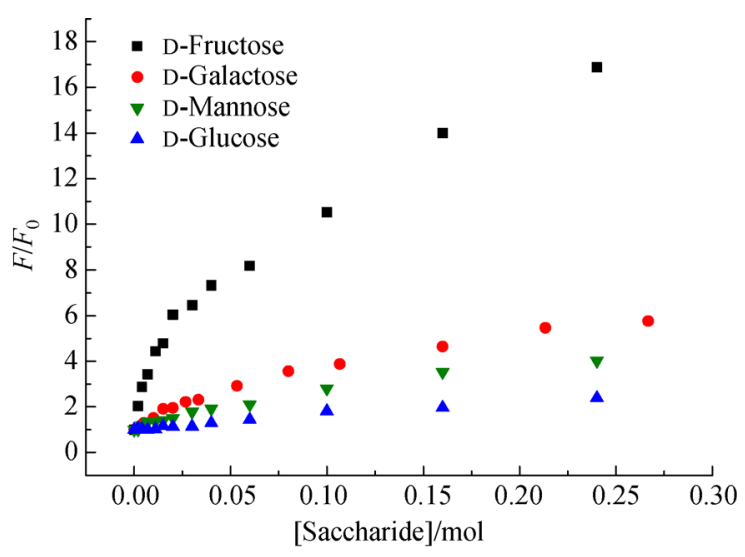

Fig. 4 Fluorescence intensity ratios of AM-5 $\left(F / F_{0}\right)$ at $409 \mathrm{~nm}$ versus monosaccharide concentration in a (1:1) $0.1 \mathrm{~mol} / \mathrm{L} \mathrm{KH}_{2} \mathrm{PO}_{4} /$ $0.1 \mathrm{~mol} / \mathrm{L} \mathrm{NaOH}, \mathrm{pH} 8.00$ buffer solution and $\lambda_{\mathrm{ex}}=370 \mathrm{~nm}$

the detection of monosaccharides was consistent with the solution titration data of $\mathbf{3}$ (Fig. 2, Table S1 and Table S2), D-fructose $>$ D-galactose $>$ D-mannose $>$ D-glucose. However, the observed binding constants for each monosaccharide were much lower than in the solution phase, which is believed to be due to the binding event being a diffusionbased process $\left((1381.7 \pm 41.80)\right.$ versus $(52.6 \pm 5.3) \mathrm{dm}^{3} /$ mol for D-fructose). The response towards D-glucose in the hydrogel was too low for the binding constant to be determined.

\section{Conclusions}

A fluorescent monosaccharide responsive hydrogel was developed by functionalising the proven ortho-aminomethylphenylboronic acid anthracene PET sensor with an acrylamide unit to incorporate into a hydrogel backbone. The boronic acid-containing hydrogel produced a significant fluorescent enhancement ( $\sim 16$ fold) with the addition of fructose and the binding stability constants followed the well-established order for binding between mono-boronic acids and saccharides: D-fructose $>\mathrm{D}$ galactose $>$ D-mannose $>$ D-glucose.

\footnotetext{
Acknowledgements The University of Bath are thanked for support. ACS thanks the EPSRC for a PhD studentship. TDJ and JSF are grateful for the support of the EPSRC and DTI (DT/F00267X/1). Preliminary results of this project stemmed from another project pump-primed by the University of Bath Enterprise Development Fund (EDF award to investigators including JSF, ATAJ and TDJ). TDJ wishes to thank the Royal Society for a Wolfson Research Merit Award. JSF and WC thanks the Leverhulme Trust for support (F00094BC). JSF thanks the JDRF (2-SRA-2016-267-A-N) for support. Spectroscopy facilities were provided through the Material and Chemical Characterisation Facility (MC2) at the University of Bath. The investigators are grateful to the CASE consortium for providing knowledge transfer and networking opportunities [36,37].
}

Electronic Supplementary Material Supplementary material is available in the online version of this article at https://doi.org/10.1007/s11705-019$1812-5$ and is accessible for authorized users.
Open Access This article is licensed under a Creative Commons Attribution 4.0 International License, which permits use, sharing, adaptation, distribution and reproduction in any medium or format, as long as you give appropriate credit to the original author(s) and the source, provide a link to the Creative Commons licence, and indicate if changes were made. The images or other third party material in this article are included in the article's Creative Commons licence, unless indicated otherwise in a credit line to the material. If material is not included in the article's Creative Commons licence and your intended use is not permitted by statutory regulation or exceeds the permitted use, you will need to obtain permission directly from the copyright holder. To view a copy of this licence, visit http://creativecommons.org/licenses/by/4.0/.

\section{References}

1. Levine R. Monosaccharides in health and disease. Annual Review of Nutrition, 1986, 6(1): 211-224

2. Mergenthaler P, Lindauer U, Dienel G A, Meisel A. Sugar for the brain: The role of glucose in physiological and pathological brain function. Trends in Neurosciences, 2013, 36(10): 587-597

3. Pickup J C, Hussain F, Evans N D, Rolinski O J, Birch D J S. Fluorescence-based glucose sensors. Biosensors \& Bioelectronics, 2005, 20(12): 2555-2565

4. Wu X, Li Z, Chen X X, Fossey J S, James T D, Jiang Y B. Selective sensing of saccharides using simple boronic acids and their aggregates. Chemical Society Reviews, 2013, 42(20): 8032-8048

5. Lorand J P, Edwards J O. Polyol complex and structure of the benzene boronate ion. Journal of Organic Chemistry, 1959, 24(6): 769-774

6. Sun X, James T D. Glucose sensing in supramolecular chemistry. Chemical Reviews, 2015, 115(15): 8001-8037

7. Huang Y J, Ouyang W J, Wu X, Li Z, Fossey J S, James T D, Jiang Y B. Glucose sensing via aggregation and the use of "knock-out" binding to improve selectivity. Journal of the American Chemical Society, 2013, 135(5): 1700-1703

8. Cao H S, Heagy M D. Fluorescent chemosensors for carbohydrates: A decade's worth of bright spies for saccharides in review. Journal of Fluorescence, 2004, 14(5): 569-584

9. James T D, Sandanayake K, Shinkai S. Novel photoinduced 
electron-transfer sensor for saccharides based on the interaction of boronic acid and amine. Journal of the Chemical Society. Chemical Communications, 1994, 0(4): 477-478

10. Zhang X T, Liu G J, Ning Z W, Xing G W. Boronic acid-based chemical sensors for saccharides. Carbohydrate Research, 2017, 452: $129-148$

11. James T D, Sandanayake K R A S, Shinkai S. A glucose-selective molecular fluorescence sensor. Angewvandte Chemie International Edition, 1994, 33: 2207-2209

12. James T D, Sandanayake K R A S, Iguchi R, Shinkai S. Novel saccharide-photoinduced electron transfer sensors based on the interaction of boronic acid and amine. Journal of the American Chemical Society, 1995, 117(35): 8982-8987

13. Franzen S, Ni W, Wang B. Study of the mechanism of electrontransfer quenching by boron-nitrogen adducts in fluorescent sensors. Journal of Physical Chemistry B, 2003, 107(47): 12942 12948

14. Ni W, Kaur G, Springsteen G, Wang B, Franzen S. Regulating the fluorescence intensity of an anthracene boronic acid system: A B-N bond or a hydrolysis mechanism? Bioorganic Chemistry, 2004, 32 (6): 571-581

15. Chapin B M, Metola P, Vankayala S L, Woodcock H L, Mooibroek T J, Lynch V M, Larkin J D, Anslyn E V. Disaggregation is a mechanism for emission turn-on of ortho-aminomethylphenylboronic acid-based saccharide sensors. Journal of the American Chemical Society, 2017, 139(15): 5568-5578

16. Sun X, James T D, Anslyn E V. Arresting "loose bolt" internal conversion from $-\mathrm{B}(\mathrm{OH})_{2}$ groups is the mechanism for emission turn-on in ortho-aminomethylphenylboronic acid-based saccharide sensors. Journal of the American Chemical Society, 2018, 140(6): $2348-2354$

17. Zhao L, Huang Q W, Liu Y, Wang Q, Wang L Y, Xiao S S, Bi F, Ding J X. Boronic acid as glucose-sensitive agent regulates drug delivery for diabetes treatment. Materials, 2017, 10 (2): 170

18. Guan Y, Zhang Y J. Boronic acid-containing hydrogels: Synthesis and their applications. Chemical Society Reviews, 2013, 42(20): $8106-8121$

19. Ahmed E M. Hydrogel: Preparation, characterization, and applications: A review. Journal of Advanced Research, 2015, 6(2): 105121

20. Li Y Y, Zhou S Q. A simple method to fabricate fluorescent glucose sensor based on dye-complexed microgels. Sensors and Actuators. B, Chemical, 2013, 177: 792-799

21. Matsumoto A, Tanaka M, Matsumoto H, Ochi K, Moro-oka Y, Kuwata H, Yamada H, Shirakawa I, Miyazawa T, Ishii H. Synthetic "smart gel" provides glucose-responsive insulin delivery in diabetic mice. Science Advances, 2017, 3, eaaq0723

22. Matsumoto A, Kataoka K, Miyahara Y. New directions in the design of phenylboronate-functionalized polymers for diagnostic and therapeutic applications. Polymer Journal, 2014, 46(8): 483-491

23. Sanjoh M, Miyahara Y, Kataoka K, Matsumoto A. Phenylboronic acids-based diagnostic and therapeutic applications. Analytical
Sciences, 2014, 30(1): 111-117

24. Sedgwick A C, Chapman R S L, Gardiner J E, Peacock L R, Kim G, Yoon J, Bull S D, James T D. A bodipy based hydroxylamine sensor. Chemical Communications, 2017, 53(75): 10441-10443

25. Sedgwick A C, Sun X L, Kim G, Yoon J, Bull S D, James T D. Boronate based fluorescence (ESIPT) probe for peroxynitrite. Chemical Communications, 2016, 52(83): 12350-12352

26. Sun X L, Odyniec M L, Sedgwick A C, Lacina K, Xu S Y, Qiang T T, Bull S D, Marken F, James T D. Reaction-based indicator displacement assay (RIA) for the colorimetric and fluorometric detection of hydrogen peroxide. Organic Chemistry Frontiers: An International Journal of Organic Chemistry, 2017, 4(6): 1058-1062

27. Sedgwick A C, Han H H, Gardiner J E, Bull S D, He X P, James T D. Long-wavelength fluorescent boronate probes for the detection and intracellular imaging of peroxynitrite. Chemical Communications, 2017, 53(95): 12822-12825

28. Wu D, Sedgwick A C, Gunnlaugsson T, Akkaya E U, Yoon J, James T D. Fluorescent chemosensors: The past, present and future. Chemical Society Reviews, 2017, 46(23): 7105-7123

29. Sedgwick A C, Han H H, Gardiner J E, Bull S D, He X P, James T D. The development of a novel AND logic based fluorescence probe for the detection of peroxynitrite and GSH. Chemical Science (Cambridge), 2018, 9(15): 3672-3676

30. Lampard E V, Sedgwick A C, Sombuttan T, Williams G T, Wannalerse B, Jenkins A T A, Bull S D, James T D. Dye displacement assay for saccharides using benzoxaborole hydrogels. ChemistryOpen, 2018, 7(3): 266-268

31. Kreisig T, Hoffmann R, Zuchner T. Homogeneous fluorescencebased immunoassay detects antigens within 90 seconds. Analytical Chemistry, 2011, 83(11): 4281-4287

32. Grabchev I, Qian X H, Xiao Y, Zhang R. Novel heterogeneous PET fluorescent sensors selective for transition metal ions or protons: Polymers regularly labelled with naphthalimide. New Journal of Chemistry, 2002, 26(7): 920-925

33. Basabe-Desmonts L, Reinhoudt D N, Crego-Calama M. Design of fluorescent materials for chemical sensing. Chemical Society Reviews, 2007, 36(6): 993-1017

34. Li M, Liu Z J, Wang H C, Sedgwick A C, Gardiner J E, Bull S D, Xiao H N, James T D. Dual-function cellulose composites for fluorescence detection and removal of fluoride. Dyes and Pigments, 2018, 149: 669-675

35. Hall D G. Boronic acids: Preparation and applications in organic synthesis, medicine and materials. Weinheim: Wiley-VCH Verlag GmbH \& Co. KGaA, 2005, 1-550

36. Fossey J S, Brittain W D G. The CASE 2014 symposium: Catalysis and sensing for our environment, Xiamen 7th-9th November 2014. Organic Chemistry Frontiers: An International Journal of Organic Chemistry, 2015, 2(2): 101-105

37. Payne D T, Fossey J S, Elmes R B P. Catalysis and Sensing for our Environment (CASE2015) and the Supramolecular Chemistry Ireland Meeting (SCI 2015): Dublin and Maynooth, Ireland. 8th11th July. Supramolecular Chemistry, 2016, 28(11-12): 921-931 